\title{
Hydrogels in wound management
}

Book or Report Section

Accepted Version

Caló, E., Ballamy, L. and Khutoryanskiy, V. V. (2018)

Hydrogels in wound management. In: Singh, T. R. R., Laverty, G. and Donnelly, R. (eds.) Hydrogels: Design, Synthesis and Application in Drug Delivery and Regenerative Medicine. CRC Press, London. ISBN 9781498748612 Available at http://centaur.reading.ac.uk/77796/

It is advisable to refer to the publisher's version if you intend to cite from the work. See Guidance on citing.

Publisher: CRC Press

All outputs in CentAUR are protected by Intellectual Property Rights law, including copyright law. Copyright and IPR is retained by the creators or other copyright holders. Terms and conditions for use of this material are defined in the End User Agreement. 


\section{CentAUR}

Central Archive at the University of Reading

Reading's research outputs online 


\section{Hydrogels in Wound Management}

Enrica Caló, ${ }^{1}$ Lucy Ballamy, ${ }^{2}$ Vitaliy V. Khutoryanskiy ${ }^{1 *}$

${ }^{1}$ University of Reading, Reading, Berkshire, RG6 6AD, United Kingdom

${ }^{2}$ ConvaTec Ltd, First Avenue-Deeside Industrial Park, Flintshire CH5 2NU, Wales, United Kingdom

"Corresponding author email address: v.khutoryanskiy@ reading.ac.uk

\subsection{Introduction}

One of the most prevalent applications of hydrogels is wound management. Thanks to their high water content and unique physical properties, hydrogels could potentially resemble biological tissues including human skin. (Peppas et al. 2000, Gupta et al. 2010, Caló \& Khutoryanskiy 2014, Jones et al. 2006) There is active interest in the development of new and advanced hydrogel-based products from both an academic and industrial perspective. In fact, hydrogels exhibit many characteristics of the 'ideal' wound dressing. These include: the capability of maintaining a moist environment at the wound site allowing gas exchange (moisture vapour transmission), biocompatibility, fast absorption of wound exudate, protection of newly formed or delicate skin and easy and relatively painless dressing removal. (Thomas 1990, Gupta et al. 2010, Vowden \& Vowden 2014, Boateng \& Catanzano 2015) In this Chapter we will provide the reader with an overview of the most recent hydrogel materials designed for wound management.

\subsection{Skin Anatomy}

The skin is considered to be the largest organ in the human body. It is responsible for protecting the body from external agents, thermoregulation and balance of water loss. (Nicol, 2005) Three different layers can be differentiated within the skin structure (Fig. 1): epidermis, dermis and subcutis (or hypodermis). The epidermis is composed of $80 \%$ keratinocytes that differentiate and migrate towards the surface (this process is called keratinization), resulting in the formation of four different 'strata' (inwards from the outer skin layer): corneum, granulosum, spinosum and basale. (Keng Wooi Ng 2015, 


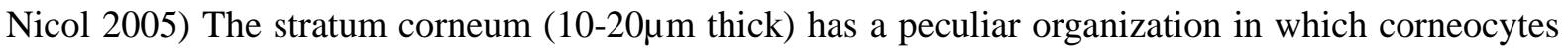
(representing the physical barrier) are arranged in the well-known 'bricks in mortar' system within the lipid matrix; the lipid matrix is composed of ceramides, free-fatty acid and cholesterol. (Michaels et al. 1975, Menon et al. 2012, van Smeden et al. 2014) This layer is always damaged when a wound occurs. It also represents one of the major obstacles in topical drug delivery.(Williams, 2003)

\subsection{Classification of Wounds}

A wound is defined as a disruption of skin integrity, which can be a symptom of a pre-existing pathological condition or be caused by mechanical, thermal or chemical damage. (Thomas, 1990) Wounds can be classified into two main types, depending on the healing time and response to treatments: acute or chronic. (Harper et al., 2014) The correct diagnosis of each wound (by identifying the causes and types of tissue present) can greatly influence the choice of treatment and the healing outcome. (Trudie, 2015)

\subsubsection{Acute Wounds}

Acute or 'superficial' wounds usually heal within a period of three weeks and involve only the epidermis and dermis (they are then called 'superficial') or they can expand into the subcutaneous layer ('full-thickness'). Abrasions, surgical wounds, burns and lacerations are considered acute wounds. (Dreifke et al., 2015) Burns can be further classified into: first-degree (resulting from exposure to moderate intensity heat and involving primarly only the epidermis), second-degree (involving a large part of the dermis as well) and third-degree or full-thickness burns (the skin is completely damaged). (Thomas, 1990)

\subsubsection{Chronic Wounds}

Chronic wounds take a minimum of eight weeks up to many years, in some cases, to heal or respond to therapy. They can seriously affect the quality of life of the patient causing mobility limitations and sometimes depression. These type of wounds are often caused by vascular, haemostaseological or metabolic disorders, as well as inflammatory skin diseases, cancer or infections. 
(Erfurt-Berge and Renner, 2015) Hospitalization is often required with consequent high costs for the healthcare system. For example, approximately 2 percent of health budgets are used for chronic wound therapies and care. (Harding et al. 2002, Schreml et al. 2010)

\subsection{The Healing Process}

Wound healing can be described as a cascade of four different events: haemostasis, inflammation, proliferation and maturation. Through this dynamic phenomenon, which requires the contribution of several molecules, cells and growth factors, the equilibrium is re-established in the body and the wound closes. (Hanna \& Giacopelli 1997, Gurtner et al. 2008) Considering the complexity of the healing cascade it is very impressive to observe how often everything proceeds without any problems. (Harper et al., 2014) In the case of chronic wounds, the process is delayed by complications such as a secondary infection, and it can take much longer for the wound to heal. (Timmons 2006) For instance, when there has been considerable tissue loss, wound closure is not immediately possible because the edges are too distant or for the presence of sepsis, in which case the microbial load must be managed so that the wound can heal without trapping bacteria inside the body. This represents the socalled closure by secondary intention, which is different from wound closure by primary intention which results from suturing wounds that involve minimal tissue loss, such as surgical incisions. (Harper et al., 2014)

\subsubsection{Haemostasis}

During haemostasis, uncontrolled blood loss is prevented and vascular integrity is restored. After tissue damage, the formation of a localized thrombus is promoted: subendothelial collagen and von Willebrand factor (vWF) are exposed on the lower face of the endothelium, stimulating platelet adhesion. Plasminogen activator inhibitor is produced, allowing fibrin generation through the proteolytic cleavage of fibrinogen by thrombin. Cross-linked fibrin then binds to platelets leading to the formation of a clot, which is visible to the naked eye. (Austin 2013, Baum \& Arpey 2006) The fibrin and platelets are the main components of the clot matrix formed, which represents an indispensable 
scaffold for all the cells that are recruited to the wound during the first steps of the healing process. (Gurtner et al. 2008, Baum \& Arpey 2006)

\subsubsection{Inflammation}

In order for the healing process to take place the fibrin clot is destroyed (through a process called fibrinolysis), facilitating cell migration to the wound site. Fluid movement to the wound is promoted through local vasodilation triggered by growth factors released from platelets, and enhancement in the permeability of capillaries in the area. (Baranoski and Ayello, 2004) The complement system (which involves a variety of different plasma proteins) is then activated: this complicated enzyme- triggered cascade is responsible for opsonization, phagocytosis and ultimately, the destruction of bacterial cells. (Charles A Janeway et al., 2001) Chemotactic substances (such as chemotaxin) are released attracting polymorphonuclear (PMN) neutrophils and monocytes, which will differentiate into macrophages. (Mulder, Magda, Small, N., Botma, Y., Ziady, L., MacKenzie, 2002) Neutrophils produce important inflammatory factors such as interleukin-1(IL-1) and tumor necrosis factor alpha (TNF- $\alpha)$, and proteases which are able to break down damaged extracellular matrix (ECM) components. Macrophages play many roles, including phagocytizing bacteria, as well as producing collagenases, elastase, other growth factors and many types of cytokines. Evident symptoms of inflammation are: erythema, swelling and an increase of the temperature in the injured area. (Granick and Teot, 2012)

\subsubsection{Proliferation}

This phase is characterized by two events that are crucial for the progress of healing: angiogenesis, which is defined as the process of formation of new blood vessels or repairing of preexiting ones allowing blood supply to the site of injury, and the production of new ECM. (Flanagan 2013, Tonnesen et al. 2000) Formation of capillary buds from vascular endothelial cells is promoted by angiogenesis factors, such as vascular endothelial growth factor (VEGF) and fibroblast growth factor2 (FGF-2). Fibroblasts migrate to the wound in response to the transforming growth factor- $\beta$ (TGF- $\beta$ ) 
which is released from macrophages, proliferate and start the production of collagen fibres and other connective tissue proteins. As a result, so-called 'granulation tissue' is formed: newly formed blood vessels within the ECM appear red and granular. (Huether and McCance, 2013) Myofibroblasts (differentiated fibroblasts, similar to smooth muscle cells due to the presence of parallel fibres in their cytoplasm) present in the granulation tissue are responsible for wound contraction, which usually starts 6 to 7 days post-injury. (Hinz et al. 2007, Huether \& McCance 2013) The choice of the initial dressing in this phase is crucial and it has to consider that any mechanical stress could lead to renewed bleeding, special care has to be taken to manage the wound and encourage the best healing outcome. (Davey and Ince, 1999)

\subsubsection{Maturation}

The maturation phase usually starts 20 days after the injury in acute wounds and it can last from six to 18 months, depending on several factors, such as skin type, age and genetic predisposition of the subject. (McCulloch \& Kloth 2010, Davey \& Ince 1999) The aim of this phase is for the injured skin to regain its strength and elasticity. This delicate process is controlled by metalloproteinases (MMPs), which are responsible for matrix tissue degradation, and their inhibitors. (Hess, 2008) Approximately $50 \%$ of the tensile strength is already regained by the wound two weeks after re-epithelization. However after having some types of wounds, especially chronic wounds, the repaired tissue may not recover completely. (Davey and Ince, 1999)

\subsection{Classification of wound dressings}

The choice of the appropriate dressing is very important and it has to be made in accordance with the overall wound management plan specific to each individual. This process is of course directly determined by the diagnosis of the wound, which is related to a great extent to the aspect and state of the wound bed (colour and tissue types present). (Vowden and Vowden, 2014) Wound dressings can be generally classified into: dry and moist products. Dry dressings, such as gauzes, are usually easily available, very cheap, indicated for low-exuding wounds and they can strongly adhere to the newly formed tissue causing painful removal. (Jones et al., 2006) Moist dressings include different types of 
materials: transparent films, hydrocolloids, alginates, foams and hydrogels. Transparent film dressings (such as Tegaderm ${ }^{\circledR}$ by $3 \mathrm{M}$ Health Care) are made from polyurethane or co-polyester and are flexible with an adhesive backing but are incapable of absorbing wound fluids, therefore they should be used on dry non-infected wounds only. (Sood et al., 2014) Hydrocolloids (such as DuoDERM ${ }^{\circledR}$ by ConvaTec) are usually composed of two layers: the inner adhesive layer in contact with the wound containing pectin, gelatin and/ or sodium carboxymethylcellulose, and the outer polyurethane layer impermeable to water. They conform to the wound surface absorbing slight to moderate amounts of exudate and they do not require frequent changes (they can be kept in place for a maximum of seven days). (Hanna and Giacopelli, 1997) Alginates (such as Kaltostat ${ }^{\circledR}$ by ConvaTec) are derived from the calcium and sodium salts of alginic acid formed in Phaeophyceae, brown seaweed. They are made up of repeating units of mannuronic and glucuronic acid and the ratio between the two units greatly influences their absorptive capacity and their tensile strength. They are suitable for medium to highly exuding wounds. (Jones et al., 2006) In the presence of high exudate, foam dressings (such as Allevyn ${ }^{\circledR}$ by Smith \& Nephew) can be used as well, because they can absorb a large amount of wound fluid within their porous structure, the limitations being that the dressing must be changed frequently so that pooling and spread of wound fluid does not cause breakdown of the surrounding skin (maceration). They are commonly represented by polyurethane or silicon foams. (Murphy and Evans, 2012). Dressings containing Hydrofiber ${ }^{\circledR}$ technology (such as AQUACEL ${ }^{\circledR}$ by ConvaTec) are made up of sodium carboxymethyl cellulose fibres. The fibres form a gel on contact with wound fluid which conforms well to the wound bed. Dressings containing Hydrofiber ${ }^{\circledR}$ technology are suitable for low to medium exudate levels and due to their gel-like nature can be easily removed from the wound bed without damaging new cells. Hydrogel dressings (which will be explored further in the next section) can be made of natural or synthetic cross-linked polymeric networks able to absorb large amounts of biological fluids. Their so-called 'moisture donor effect' promotes collagenase production accelerating autolytic debridement of necrotic wounds. (Stashak et al., 2004)

\subsection{Hydrogel-based products for wound care}


Although hydrogels are now recognized as an alternative to more conventional wound care products, they are not routinely employed and there are few products currently available on the market. The high production and final costs may prevent the industry from manufacturing these materials on a large scale and healthcare professionals from extensively using them on patients. (Caló \& Khutoryanskiy 2014, Sood et al. 2014) Hydrogel-based products for wound care are usually designed as flat transparent sheets, which are very useful for instance in the treatment of pressure wounds, or as amorphous gels, which can be applied to wounds at difficult anatomical locations such as cavity wounds (acting as fillers) (Figs. 2 and 3). (Jones and Vaughan, 2005) However, independently from the shape or design, all hydrogel products must exhibit specific characteristics, such as very high absorption capacity, moisture donation capability, transparency, good mechanical properties and biocompatibility in order to have the best performance. (Holbock, Y, Yeao Y., 2011)

\subsubsection{Commercially available hydrogels}

The wound management industry has experienced a period of incredible development in the last decades, continuously designing more advanced technologies and products.(Schreml et al., 2010) Since Winter (1962) established that a moist environment effectively helps and accelerates wound healing, moist wound dressings, such as hydrogels, started gaining popularity over gauze and dry materials.(Jones 2005, Jones \& Vaughan 2005, Jones et al. 2006) Whilst bearing in mind that the 'perfect' dressing for every type of wound and every stage of healing would be very difficult to create, efforts have been made to manufacture new products with specific features (such as particular designs for an easier application or active ingredients added) and keeping the final prices as low as possible. (Jones et al. 2006, Leaper 2006) We will mention a few in order to give the reader an idea of the range of hydrogel-based products for wound care now available on the market.

Granugel ${ }^{\circledR}($ ConvaTec) is an amorphous clear hydrogel containing pectin, carboxymethyl cellulose and propylene glycol. It is indicated for the management of partial and full-thickness wound (such as leg and pressure ulcers). (Williams, 1996) Intrasite $^{\circledR}$ Gel (Smith \& Nephew) is made from modified 
carboxymethyl cellulose and propylene glycol and it is used for surgical wounds, venous ulcers, diabetic foot and pressure ulcers. It is relatively simple to apply thanks to an applicator (Applipak system) and is available in different sizes. (Williams 1994, Vernon 2000, Eaglstein 2001) Purilon ${ }^{\circledR}$ Gel (Coloplast) also has an applicator, and it is composed of sodium carboxymethyl cellulose, calcium alginate and water. It is usually used in conjunction with a secondary dressing, on dry and necrotic wounds. (Caló and Khutoryanskiy, 2014) Aquaform ${ }^{\mathrm{TM}}$ (Aspen Medical), more specifically its newer version, contains glycerol, starch copolymer, methylparaben and imidazolidyl urea (as preservatives) and purified water. It can be used on flat and cavity wounds with low or no exudate. (Timmons et al., 2008) Aquaflo ${ }^{\circledR}$ (Covidien) is a flat hydrogel dressing and is produced from polyethylene glycol and propylene glycol. It has a unique disc shape and is transparent to aid monitoring of the wound. First Water Ltd., which was recently acquired by Scapa Group plc, manufactures Woundtab ${ }^{\circledR}$, a flat hydrogel containing carboxymethylcellulose, sulphonated copolymer, glycerol and water indicated for chronic wounds. (Caló and Khutoryanskiy, 2014) Another well-known hydrogel composition is a Kikgel $^{\mathrm{TM}}$ developed by Rosiak et al., which is made from the combination of a natural polymer (such as agar) and a synthetic one (such as poly vinyl pyrrolidone) crosslinked by gamma radiation (Rosiak 1995, Dabbagh et al. 2010), this dressing is intended for chronic ulcers and burns. Nu-Gel ${ }^{\circledR}$ (Systagenix) is a hydrogel dressing made of polyvinyl pyrrolidone and water, indicated for dry, partial and full-thickness wounds. (Ovington 2007, Eaglstein 2001)

Hydrogel wound care products now often contain active ingredients such as antimicrobial agents in order to prevent bacteria colonization of the wound and infections that would delay healing.(Leaper, 2006) For instance, colloidal or ionic silver has been proposed in several wound care products as an efficient antimicrobial to be used against pathogens such as Pseudomonas aeruginosa and Staphylococcus aureus. (Foster 1996, Seth et al. 2012) Silvasorb ${ }^{\circledR}$ (Medline) is a polyacrylate gel produced using the MicroLattice ${ }^{\mathrm{TM}}$ technology, containing ionic silver. It is suitable for chronic deep wounds with moderate drainage and can be changed every 3 (amorphous form) to 7 days (gel sheets). (Hess 2008, Ovington 2007) Povidone-iodine loaded hydrogel dressings became very popular as well, 
such as Vigilon $^{\mathrm{TM}}$ (Bard, distributed by Seton Healthcare Group plc), and are claimed to inhibit bacteria growth and proliferation at the wound site. (Mertz et al., 1986)

\subsubsection{Future hydrogel technologies}

Academia is the cradle of new ideas and exciting findings par excellence, which has always inspired industry. Many research projects for the development of advanced wound care technologies have been successful resulting from productive collaborations between academia and industry, and have led to significant progress in the field. (Salcido, 1999) From simple dressings, hydrogels become systems for the delivery of agents that can accelerate the healing process and actually make a big difference to the condition of patients. Gong et al. (Gong et al., 2013) proposed a thermosensitive in-situ forming hydrogel containing curcumin loaded micelles, which reported very good in vitro wound healing activity. The composite made of poly(ethylene glycol)-poly( $\varepsilon$-caprolactone)-poly(ethylene glycol) (PEG-PCL-PEG), would gel at body temperature adhering to the tissue and offering a sustained release of curcumin over a period of 14 days. Curcumin (extracted from the rhizome of Curcuma longa) has been used as a traditional medicine in Southeast Asia for its anti-oxidant, anti-bacterial and antiinflammatory activities. However, it has poor solubility in water and oral bioavailability, problems that have been bypassed using this system. (Gong et al., 2013) Miguel et al. (Miguel et al., 2014) presented an in-situ thermoresponsive and antimicrobial chitosan-agarose hydrogel that accelerates skin regeneration. In vitro (using human dermal fibroblasts), and in vivo (using Wistar rats) testing reported, shows that this material is able to allow cell migration and proliferation, and to enhance autolytic debridement, promoting re-epithelization. Patients with burns can present particularly unpleasant scarring and may benefit from formulations such as this. (Miguel et al., 2014) Burns can also have prolonged recovering (up to 10 weeks) especially when the dermis is compromised (full and partialthickness burns). Loo et al. (Loo et al., 2014) designed a very interesting hydrogel, formed from ultrashort peptides (motif composed of three to seven aliphatic amino acids) in a nanofibrous network, that can be used as a primary dressing for these types of burn injuries. These peptides undergo selfassembly in aqueous conditions and can retain up to $99.9 \%$ of water, as the peptides convert into hydrogels, they are able to keep the wound hydrated and can be removed easily. The resemblance of 
the network formed with the ECM facilitates cell adhesion and tissue regeneration, resulting in a faster healing when compared with the standard dressing.(Loo et al., 2014) Reyes-Ortega et al. (Reyes-Ortega et al., 2015) loaded a gelatin/hyaluronic acid hydrogel with proadrenomedullin N-terminal 20 peptide (PAMP). This peptide naturally occurs in the skin and it is known for its proangiogenic, antiinflammatory and antibacterial activities. The system presented in this work is composed of two different sections, both bio-functionalized. The external layer is made of polyurethane and loaded with bioresorbable nanoparticles containing bemiparin (low molecular weight form of heparin able to complex with growth factors such as FGF and VEGF enhancing their activity). The internal layer is represented by the biodegradable hydrogel releasing PAMP to the wound. This dressing has been proposed for the compromised wounds, such as diabetic ulcers, or in the presence of problematic epidermal regeneration, as in the elderly. (Reyes-Ortega et al., 2015) One of the most popular strategies to speed up healing is indeed the delivery of peptides, polysaccharides and other molecules that naturally take part in this process. For instance, hyaluronic acid (HA), present in the aforementioned work as well, has been extensively explored for the role that it plays in the early stages, promoting keratinocytes proliferation and migration. Catanzano et al. (Catanzano et al., 2015) developed a hydrogel dressing made of alginate (ALG) and HA by internal gelation, the technique that involves the slow release of calcium ions which can form complexes with ALG leading to the formation of an ionically cross-linked homogenous network without the addition of any toxic cross-linking agents. Here, the presence of HA was shown to significantly reduce the time to wound closure as demonstrated by the in vivo excision wound model carried out on rats. (Catanzano et al., 2015) Researchers are also considering natural molecules extractable from different sources such as bacteria and insects. A good example is the work presented by Shi et al. (Shi et al., 2015) that combined poly $(\gamma$-glutamic acid) $(\gamma$ PGA, polyamino acid secreted by some Bacilli) and silk sericin (SS, protein obtained from silkworm Bombyx mori) to produce an antibacterial hydrogel dressing. (Shi et al., 2015) Chitosan-based hydrogel products have been widely investigated because of chitosan's intrinsic activity against bacteria and fungi, and of course due to the biocompatibility of this polymer, but no products are known to have been commercialized yet. (Paul \& Sharma 2004, Sparkes et al 1986) 
When the wound is microscopic in size or affects particularly delicate organs of the body such as the eyes, treatment can be very challenging. Tsai et al. (Tsai et al., 2016) proposed a thermosensitive chitosan/gelatine/glycerophosphate hydrogel for the delivery of ferulic acid (FA) to corneal burns that may be caused by chemicals or ultraviolet-B light exposure. In this condition, an abnormal production of reactive oxygen species (ROS) is often observed, and it can be very hard for the endogenous antioxidant system to manage this high level. FA is a polyphenol, natural anti-oxidant compound that can prevent ROS damages. However, it has low bioavailability and residence time when administered topically in the eye. Its inclusion in the hydrogel system presented by Tsai et al. allows its successful sustained release to the cornea with very interesting clinically relevant results in vitro and in vivo. (Tsai et al., 2016)

\subsection{Conclusions}

Hydrogels represent an excellent choice of treatment for many types of wounds, which can be difficult to manage with traditional dry dressings. However, patients would benefit from more advanced, efficient, cost-effective hydrogel products in order to significantly enhance healing time and quality. For these reasons, it is important that industry and academia continue to join their efforts and expertise. In future, it is hoped that specific novel computer technologies and equipment will enable the development of improved wound management techniques. For instance, new wound image evaluation systems such as the one proposed by Veredas et al. (Veredas et al., 2015) could give healthcare professionals a great help establishing the correct diagnosis in the shortest possible time. (Veredas et al. 2015, Engel et al. 2011) The healthcare system, which annually sustains huge costs for the treatment of chronic wounds (of non-hospitalized and hospitalized patients), would greatly benefit, from innovative low-cost hydrogel-based wound care solutions for routine use. (Ramos et al. 2015, Sen et al. 2009)

\section{Acknowledgements}

The authors would like to thank the University of Reading and ConvaTec Ltd. for funding Enrica Caló's $\mathrm{PhD}$ project. The authors confirm that there is no conflict of interest. 
$\circledR / \mathrm{TM}$ all trademarks are the property of their respective owners.

\section{References}

Austin, S.K., 2013. Haemostasis. Medicine (Baltimore). 41, 208-211.

Baranoski, S., Ayello, E.A., 2004. Wound Care Essentials: Practice Principles. Lippincott Williams \& Wilkins, Philadelphia, USA.

Baum, C.L., Arpey, C.J., 2006. Normal Cutaneous Wound Healing: Clinical Correlation with Cellular and Molecular Events. Dermatologic Surg. 31, 674-686.

Boateng, J., Catanzano, O., 2015. Advanced Therapeutic Dressings for Effective Wound Healing-A Review. J. Pharm. Sci. 1-28.

Caló, E., Khutoryanskiy, V. V., 2014. Biomedical applications of hydrogels: a review of patents and commercial products. Eur. Polym. J. 65, 252-267.

Catanzano, O., D’Esposito, V., Acierno, S., Ambrosio, M.R., Caro, C. De, Avagliano, C., Russo, P., Russo, R., Miro, A., Ungaro, F., Calignano, A., Formisano, P., Quaglia, F., 2015. AlginateHyaluronan Composite Hydrogels Accelerate Wound Healing Process. Carbohydr. Polym. 131, 407-414.

Charles A Janeway, J., Travers, P., Walport, M., Shlomchik, M.J., 2001. Immunobiology: The Immune System in Health and Disease. 5th edition. Garland Science, New York, USA.

Dabbagh, M., Moghimipour, E., Ameri, A., Sayfoddin, N., 2010. Physicochemical Characterization and Antimicrobial Activity of Nanosilver Containing Hydrogels. Iran. J. Pharm. Res. 21-28.

Davey, A., Ince, C.S., 1999. Fundamentals of Operating Department Practice. Cambridge University Press, Cambridge, UK.

Dreifke, M.B., Jayasuriya, A.A., Jayasuriya, A.C., 2015. Current wound healing procedures and potential care. Mater. Sci. Eng. C 48, 651-662.

Eaglstein, W.H., 2001. Moist Wound Healing with Occlusive Dressings: A Clinical Focus. Dermatologic Surg. 27, 175-182.

Engel, H., Huang, J.J., Tsao, C.K., Lin, C.-Y., Chou, P.-Y., Brey, E.M., Henry, S.L., Cheng, M.H., 2011. Remote real-time monitoring of free flaps via smartphone photography and $3 \mathrm{G}$ wireless Internet: a prospective study evidencing diagnostic accuracy. Microsurgery 31, 589-95.

Erfurt-Berge, C., Renner, R., 2015. Chronic wounds - Recommendations for diagnostics and therapy. Rev. Vasc. Med. 3, 5-9.

Flanagan, M., 2013. Wound Healing and Skin Integrity: Principles and Practice. John Wiley \& Sons, Oxford, UK.

Foster, T., 1996. Staphylococcus, in: Baron, S. (Ed.), Medical Microbiology. University of Texas Medical Branch at Galveston, Galveston (USA), p. Chapter 12. 
Gong, C., Wu, Q., Wang, Y., Zhang, D., Luo, F., Zhao, X., Wei, Y., Qian, Z., 2013. A biodegradable hydrogel system containing curcumin encapsulated in micelles for cutaneous wound healing. Biomaterials 34, 6377-87.

Granick, M.S., Teot, L., 2012. Surgical Wound Healing and Management, 2nd ed. CRC Press, Boca Raton (USA).

Gupta, B., Agarwal, R., Alam, M.S., 2010. Textile-based smart wound dressings. Indian J. Fibre Text. Res. 35, 174-187.

Gurtner, G.C., Werner, S., Barrandon, Y., Longaker, M.T., 2008. Wound repair and regeneration. Nature 453, 314-21.

Hanna, J.R., Giacopelli, J.A., 1997. A review of wound healing and wound dressing products. J. Foot Ankle Surg. 36, 2-14.

Harding, K.G., Morris, H.L., Patel, G.K., 2002. Clinical review Healing chronic wounds 160-163.

Harper, D., Young, A., McNaught, C.-E., 2014. The physiology of wound healing. Surg. 32, 445-450.

Hess, C.T., 2008. Skin and Wound Care. Lippincott Williams \& Wilkins, Philadelphia (USA).

Hinz, B., Phan, S.H., Thannickal, V.J., Galli, A., Bochaton-Piallat, M.-L., Gabbiani, G., 2007. The myofibroblast: one function, multiple origins. Am. J. Pathol. 170, 1807-16.

Holbock, Y, Yeao Y., P.K., 2011. Hydrogel swelling behavior and its biomedical applications. pp.343 In: S. Rimmer [ed.] Biomedical Hydrogels: Biochemistry, Manufacture and Medical Applications. Woodhead Publishing Materials, Philadelphia, USA.

Huether, S.E., McCance, K.L., 2013. Understanding Pathophysiology, 5th ed. Elsevier Health Sciences, Saint Louis (USA).

Jones, A., Vaughan, D., 2005. Hydrogel dressings in the management of a variety of wound types: A review. J. Orthop. Nurs. 9, S1-S11.

Jones, J., 2005. Winter's concept of moist wound healing: a review of the evidence and impact on clinical practice. J. Wound Care 14, 273-6.

Jones, V., Grey, J.E., Harding, K.G., 2006. Wound dressings. BMJ 332, 777-80.

Keng Wooi Ng, W.M.L., 2015. Skin Deep: The Basics of Human Skin Structure and Drug Penetration, in: Percutaneous Penetration Enhancers 3 Chemical Methods in Penetration Enhancement: Drug Manipulation Strategies and Vehicle Effects. (O) Springer-Verlag Berlin Heidelberg, pp. 3-11.

Leaper, D.J., 2006. Silver dressings: their role in wound management. Int. Wound J. 3, 282-94.

Loo, Y., Wong, Y.-C., Cai, E.Z., Ang, C.-H., Raju, A., Lakshmanan, A., Koh, A.G., Zhou, H.J., Lim, T.-C., Moochhala, S.M., Hauser, C.A.E., 2014. Ultrashort peptide nanofibrous hydrogels for the acceleration of healing of burn wounds. Biomaterials 35, 4805-14.

McCulloch, J.M., Kloth, L.C., 2010. Wound Healing: Evidence-Based Management, 4th ed. F.A. Davis, Philadelphia (USA). 
Menon, G.K., Cleary, G.W., Lane, M.E., 2012. The structure and function of the stratum corneum. Int. J. Pharm. 435, 3-9.

Mertz, P.M., Marshall, D.A., Kuglar, M.A., 1986. Povidone-iodine in polyethylene oxide hydrogel dressing. Effect on multiplication of Staphylococcus aureus in partial-thickness wounds. Arch. Dermatol. 122, 1133-8.

Michaels, A.S., Chandrasekaran, S.K., Shaw, J.E., 1975. Drug permeation through human skin: Theory andinvitro experimental measurement. AIChE J. 21, 985-996.

Miguel, S.P., Ribeiro, M.P., Brancal, H., Coutinho, P., Correia, I.J., 2014. Thermoresponsive chitosan-agarose hydrogel for skin regeneration. Carbohydr. Polym. 111, 366-73.

Mulder, Magda, Small, N., Botma, Y., Ziady, L., MacKenzie, J., 2002. Basic Principles of Wound Care. Pearson South Africa, Cape Town (South Africa).

Murphy, P.S., Evans, G.R.D., 2012. Advances in wound healing: a review of current wound healing products. Plast. Surg. Int. 2012, 1-7.

Nicol, N.H., 2005. Anatomy and physiology of the skin. Dermatol. Nurs. 17, 3-11.

Ovington, L.G., 2007. Advances in wound dressings. Clin. Dermatol. 25, 33-8.

Peppas, N.A., Bures, P., Leobandung, W., Ichikawa, H., 2000. Hydrogels in pharmaceutical formulations 50, 27-46.

Ramos, A., Morillo, J.M., Gayo, N., Tasiguano, J.E., Munzón, E., Ribeiro, A.S.F., 2015. Curar o paliar: ¿qué cuesta más? Análisis de costes del tratamiento de una herida crónica en función de su finalidad. Med. Paliativa 22, 45-51.

Reyes-Ortega, F., Cifuentes, A., Rodríguez, G., Aguilar, M.R., González-Gómez, Á., Solis, R., García-Honduvilla, N., Buján, J., García-Sanmartin, J., Martínez, A., Román, J.S., 2015. Bioactive bilayered dressing for compromised epidermal tissue regeneration with sequential activity of complementary agents. Acta Biomater.

Rosiak, J.M., 1995. Pergamon radiation formation of hydrogels for biomedical purposeses. Some remarks and comments. Radiat. Phys. Chem. 46, 161-168.

Salcido, R., 1999. Research partnerships: academia, industry, patients, and clinicians. Adv. Wound Care 12, 231-2.

Schreml, S., Szeimies, R.-M., Prantl, L., Landthaler, M., Babilas, P., 2010. Wound healing in the 21st century. J. Am. Acad. Dermatol. 63, 866-81.

Sen, C.K., Gordillo, G.M., Roy, S., Kirsner, R., Lambert, L., Hunt, T.K., Gottrup, F., Gurtner, G.C., Longaker, M.T.,. Human skin wounds: a major and snowballing threat to public health and the economy. Wound Repair Regen. 17, 763-71.

Seth, A.K., Geringer, M.R., Gurjala, A.N., Hong, S.J., Galiano, R.D., Leung, K.P., Mustoe, T.A., 2012. Treatment of Pseudomonas aeruginosa biofilm-infected wounds with clinical wound care strategies: a quantitative study using an in vivo rabbit ear model. Plast. Reconstr. Surg. 129, $262 \mathrm{e}-274 \mathrm{e}$. 
Shi, L., Yang, N., Zhang, H., Chen, L., Tao, L., Wei, Y., Liu, H., Luo, Y., 2015a. A novel poly( $\gamma$ glutamic acid)/silk-sericin hydrogel for wound dressing: Synthesis, characterization and biological evaluation. Mater. Sci. Eng. C 48, 533-540.

Sood, A., Granick, M.S., Tomaselli, N.L., 2014. Wound Dressings and Comparative Effectiveness Data. Adv. wound care 3, 511-529.

Stashak, T.S., Farstvedt, E., Othic, A., 2004. Update on wound dressings: Indications and best use. Clin. Tech. Equine Pract. 3, 148-163.

Thomas, S., 1990. Wound Management and Dressings. Pharmaceutical Press, London (UK).

Timmons J., 2006. Skin function and wound healing physiology. Wound Essentials 1, 9-17.

Timmons, J., Bertram, M., Pirie, G., Duguid, K., 2008. Aquaform?? hydrogel - A new formulation for an improved wound care performance. Wounds UK 4, 69-73.

Tonnesen, M.G., Feng, X., Clark, R.A., 2000. Angiogenesis in wound healing. J. Investig. Dermatol. Symp. Proc. 5, 40-6.

Trudie, Y., 2015. Accurate assessment of different wound tissue types. Wound Essentials 10, 51-54.

Tsai, C.-Y., Woung, L.-C., Yen, J.-C., Tseng, P.-C., Chiou, S.-H., Sung, Y.-J., Liu, K.-T., Cheng, Y.H., 2016. Thermosensitive chitosan-based hydrogels for sustained release of ferulic acid on corneal wound healing. Carbohydr. Polym. 135, 308-315.

Van Smeden, J., Janssens, M., Gooris, G.S., Bouwstra, J.A., 2014. The important role of stratum corneum lipids for the cutaneous barrier function. Biochim. Biophys. Acta 1841, 295-313.

Veredas, F.J., Luque-Baena, R.M., Martín-Santos, F.J., Morilla-Herrera, J.C., Morente, L., 2015. Wound image evaluation with machine learning. Neurocomputing 164, 112-122.

Vernon, T., 2000. Intrasite Gel and Intrasite Conformable: the hydrogel range. Br. J. Nurs. 9, 1083-8.

Vowden, K., Vowden, P., 2014. Wound dressings: principles and practice. Surg. 32, 462-467.

Williams, A., 2003. Transdermal and Topical Drug Delivery from Theory to Clinical Practice. Pharmaceutical Press, London (UK).

Williams, C., 1996. Granugel: hydrocolloid gel. Br. J. Nurs. 5, 188, 190. doi:10.12968/bjon.1996.5.3.188

Williams, C., 1994. Intrasite Gel: a hydrogel dressing. Br. J. Nurs. 3, 843-6. 


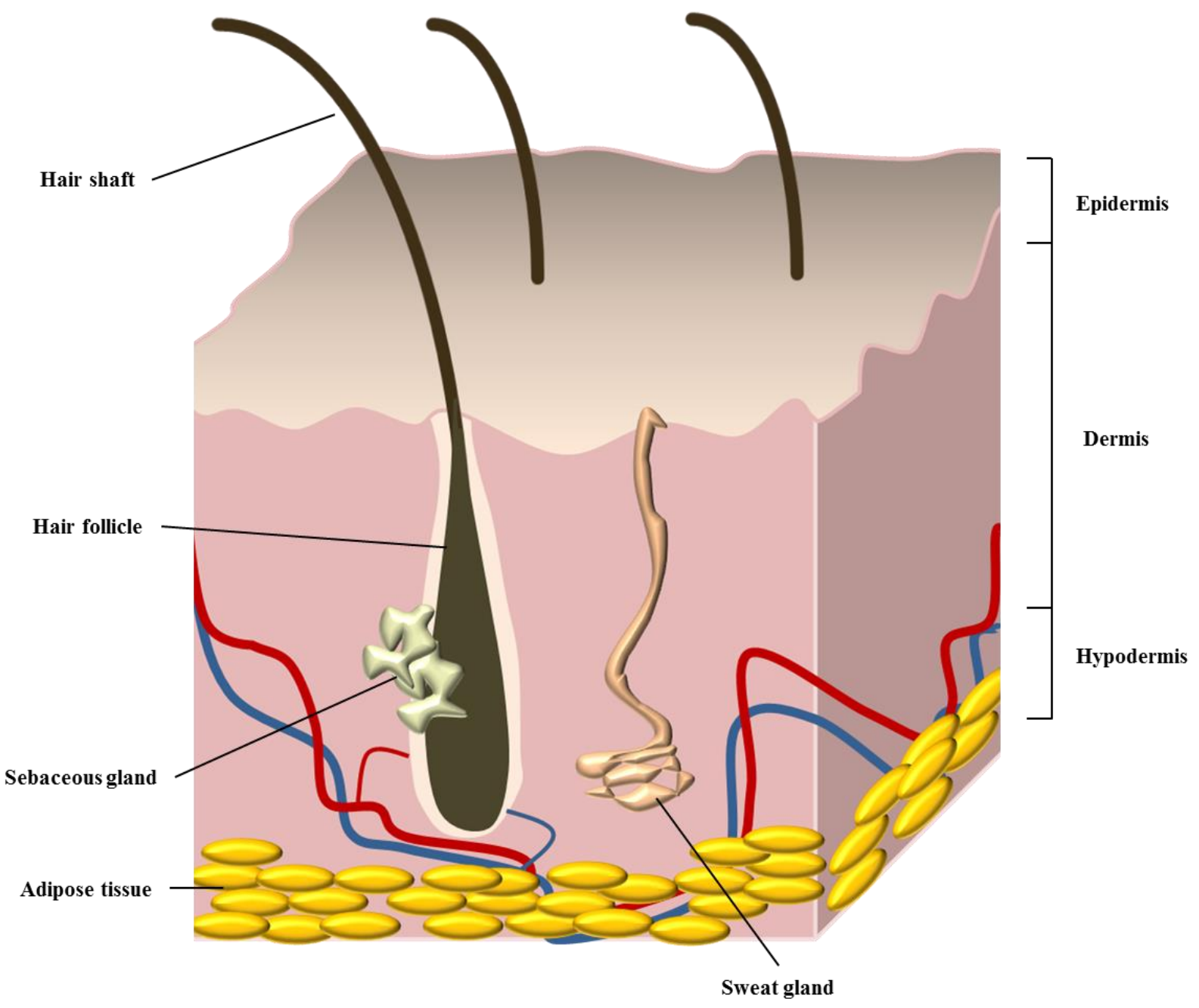

Figure 1. Schematical representation of human skin structure

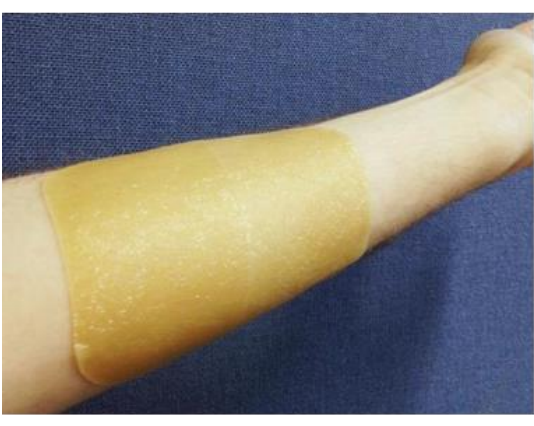

Flat hydrogel

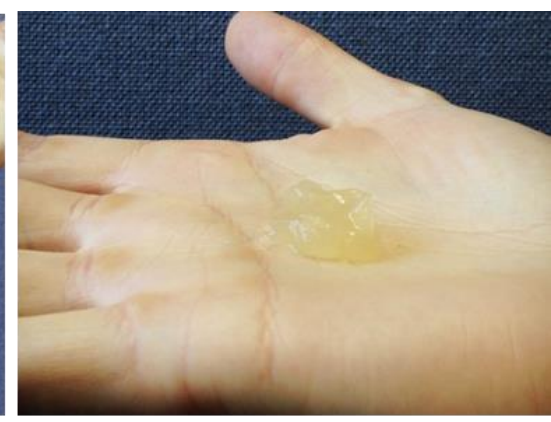

Amorphous hydrogel

Figure 2. Flat and amorphous hydrogel products for wound care. 


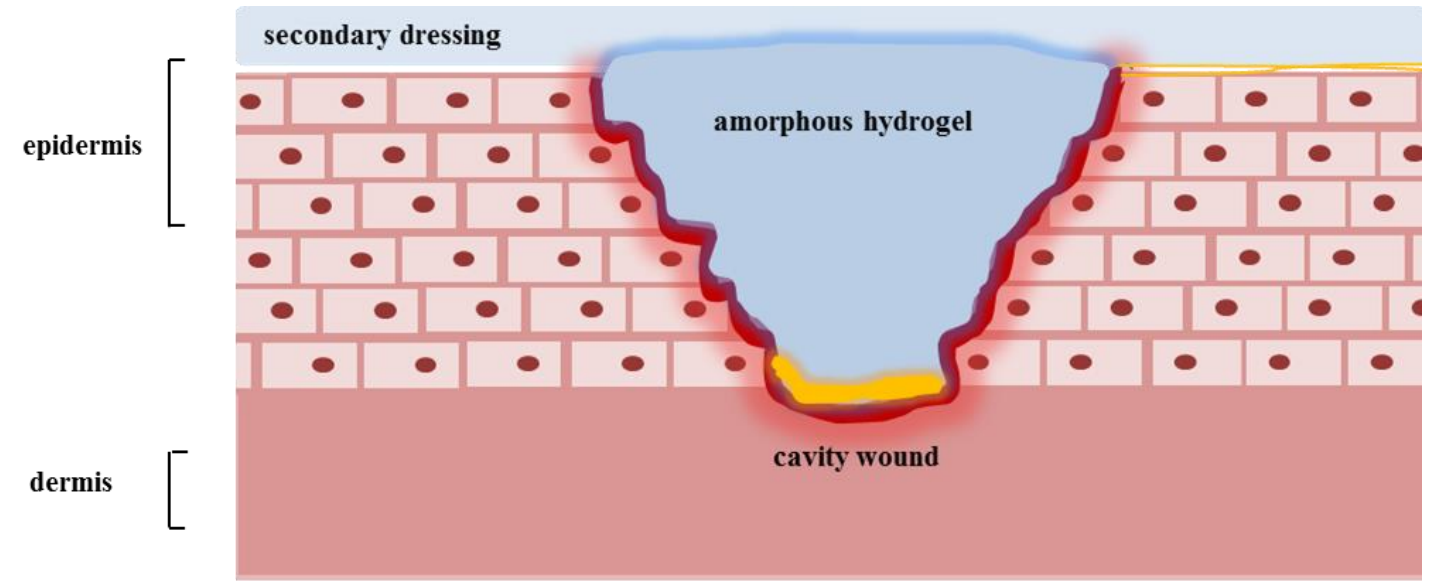

Figure 3. Amorphous hydrogel acting as filler in cavity wound. 